\title{
VARIAÇÃO DO GRAU DE DORMÊNCIA EM SEMENTES DE Stylosanthes scabra DE TRÊS REGIÕES ECOGEOGRÁFICAS DO ESTADO DE PERNAMBUCO
}

\author{
Rosilda de Melo Queiroz', Valderez Pontes $\operatorname{Matos}^{2}$ \& Clodoaldo J. da Anunciação Filhoª
}

\begin{abstract}
RESUMO
Com o presente trabalho, objetivou-se avaliar a variabilidade genética de populações de Stylosanthes scabra (Alfafa do Nordeste) como resultado de estratégia adaptativa a diferentes ambientes das regiões Mata, Agreste e Sertão do Estado de Pernambuco. Grande variabilidade interpopulacional foi encontrada quanto à percentagem de germinação de sementes não escarificadas. As populações procedentes do Sertão, quando comparadas às da Mata e Agreste, apresentaram capacidade de germinação inferior sugerindo, assim, que adquiriram condições favoráveis à dormência, como provável resposta às adversidades ambientais daquela região.
\end{abstract}

Palavras-chave: germinação, dormência, evolução

\section{VARIATION OF DORMANCY EXTENT OF Stylosanthes scabra SEEDS FROM THREE ECOGEOGRAPHIC REGIONS OF PERNAMBUCO}

\begin{abstract}
This study aimed at evaluating the genetic variability of Stylosanthes scabra (Alfafa of Northeast) populations as a result of the adaptation strategy to different environments from the regions: Mata, 'Agreste' and 'Sertão' in the state of Pernambuco. A great interpopulational variability relative to the germination of non scarified seeds was encountered. Populations from 'Sertão', when compared to the ones from 'Mata' and 'Agreste', showed an inferior germination capacity, suggesting that they acquired favorable conditions to dormancy, probably in response to the environmental adversities in that region.
\end{abstract}

Key words: germination, dormancy, evolution

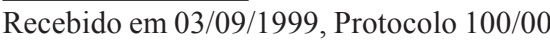

${ }^{1}$ Bióloga Ms., Departamento de Biologia, UFRPE/Recife, PE. Universidade Federal Rural de Pernambuco, Departamento de Biologia, Rua Manoel de Medeiros, s/n, CEP 52171 - 030, Recife, PE. Fone: (0xx81) 3445 0596, Fax: (0xx81) 34452093. Email: rosilda@biogate.com

${ }^{2}$ Professora Adjunta Doutora, Departamento de Agronomia, UFRPE/Recife, PE. Fone: (0xx81) 3466 9348, Fax: (0xx81) 34414798. Email: prpqpg@girnpde.ufrpe.br

${ }^{3}$ Professor Adjunto Doutor, Departamento de Agronomia, UFRPE/Recife, PE. Fone: (0xx81) 3227 4785, Fax: (0xx81) 3441 4798 


\section{INTRODUÇÃO}

Sementes dormentes são aquelas que, embora viáveis, não germinam em condições apropriadas à germinação, como o fornecimento de temperatura favorável e adequado suprimento de água e oxigênio (Roberts, 1972, Mayer \& Poljakoff-Mayber, 1975, Carvalho \& Nakagava, 2000).

De acordo com Mayer \& Poljakoff-Mayber (1975), Popinigis (1977), Humphreys (1981) e Silva \& Matos (1993/94) a origem ou causa da dormência de sementes pode estar relacionada ao tegumento da semente ou estruturas associadas que: (1) impedem a entrada de água; (2) oferecem resistência mecânica, impedindo o desenvolvimento do embrião; (3) afetam as trocas gasosas e (4) contêm substâncias inibidoras da germinação; por outro lado, no entanto, ela pode estar associada ao embrião, que pode (1) ser imaturo ou rudimentar; (2) ser fisiologicamente inativo e (3) sofrer de dormência secundária induzida por mudança ambiental posterior à maturação da semente. A dormência pode ser também resultante da combinação de duas ou mais causas.

Um dos mecanismos ou causas da dormência, de valor altamente adaptativo, é atribuído à impermeabilidade do tegumento da semente à água, característica esta de ocorrência comum em muitas espécies de leguminosas forrageiras, entre elas as do gênero Stylosanthes, e constitui um dos fatores de importância fundamental para a persistência e regeneração dessas leguminosas em pastagens. As sementes com tegumento impermeável à água, comumente denominadas sementes duras, podem permanecer viáveis no solo durante longo período de tempo, constituindo uma reserva da qual algumas sementes se tornam permeáveis à água e germinam em intervalos sucessivos, quando as condições ambientais são favoráveis (Rolston, 1978).

Estudos sobre o controle genético da dormência de sementes, mais especificamente do caráter semente dura em leguminosas forrageiras, são poucos. No que se refere ao tipo de herança desse caráter, trabalhos realizados com espécies dos gêneros Vicia (Donnelly et al., 1972) e Lupinus (Forbes \& Wells, 1968; Gladstone, 1970) envolvendo cruzamentos intra e/ou interespecíficos, indicaram que a característica de impermeabilidade à água apresentada pelo tegumento da semente tem controle genético qualitativo.

Estudando diferentes populações de Stylosanthes guianensis (Ausl.) Sw., Paterniani \& Martins (1979), evidenciaram a existência de ampla variabilidade entre as populações no que se refere ao grau de dormência das sementes; esta variabilidade deve ter um grande componente genético, pois as populações eram oriundas de diferentes localidades e foram submetidas a condições ambientais uniformes e controladas. Do ponto de vista do melhoramento de plantas, este fato tem implicação importante, pois sugere a possibilidade de se proceder à seleção de variedades com maior ou menor porcentagem de sementes duras, conforme os objetivos do programa de melhoramento.

Donelly et al. (1972) concluíram que a herança do caráter semente dura em Vicia sativa é controlada por mais de dois genes: o gene $\mathrm{A}$, como único dominante para o caráter semente dura e o gene B, como dominante para semente permeável, quando o locus A é homozigoto recessivo (aa) e o genótipo duplo homozigoto (aabb) condiciona semente dura.
A ocorrência de sementes duras em leguminosas tem sido atribuída tanto a fatores genéticos como ambientais (Donnelly, 1970).

Argel \& Humphreys (1981) observaram que a impermeabilidade do tegumento da semente de Stylosanthes hamata cv. Verano estava associada à temperatura que prevalecia durante a formação das sementes. Em testes de germinação, realizados por ocasião da colheita, foram observadas elevadas percentagens de sementes duras quando a temperatura do ar, durante o período de formação da semente, era mais alta, ocorrendo redução gradativa desse percentual à medida que a temperatura na referida fase se tornava mais baixa. Este trabalho demonstra, portanto, a influência de um componente ambiental sobre a variação do grau de dormência das sementes de $S$. hamata cv. Verano.

Battistin (1981) avaliou a germinação de sete espécies e três variedades do gênero Stylosanthes em regimes de temperatura constante: 15,25 e $35{ }^{\circ} \mathrm{C}$. Todas as espécies e variedades apresentaram alta porcentagem de sementes dormentes, refletindo baixa variabilidade dentro de cada temperatura. A percentagem média de dormência foi de $90,19 \%$ a $15{ }^{\circ} \mathrm{C}$, $90,53 \%$ a $25^{\circ} \mathrm{C}$ e $91,36 \%$ a $35^{\circ} \mathrm{C}$; entretanto, o autor observou comportamento diferencial entre as espécies, no que se refere à taxa de velocidade de germinação das sementes, nas diferentes temperaturas.

Informações sobre o controle genético do caráter semente dura em leguminosas forrageiras, são praticamente inexistentes para as espécies tropicais de modo geral, entre as quais se incluem as do gênero Stylosanthes (Reis, 1984).

Trabalhos desenvolvidos em diferentes espécies de Stylosanthes (Barriga, 1979; Paterniani \& Martins, 1979; Battistin, 1981; Reis, 1984 e Vieira, 1987) evidenciaram a existência de ampla variabilidade intra e interespecífica com relação à percentagem de sementes duras e indicaram, ainda, que tal variabilidade apresenta, provavelmente, um componente ambiental e outro genético, resultado da pressão de seleção em ambientes heterogêneos.

A escassez de pastagens nas épocas secas no semi-árido nordestino tem-se constituído num forte estímulo para que pesquisadores despertem para a necessidade de se estudar as forrageiras nativas. As espécies do gênero Stylosanthes são leguminosas nativas com alto potencial forrageiro e bem adaptadas às condições edafoclimáticas do Nordeste, seu estudo é de fundamental importância para futuros trabalhos de melhoramento.

O presente trabalho teve como objetivo verificar a influência de fatores ecológicos na germinação de sementes de Stylosanthes scabra.

\section{MATERIAL E MÉTODOS}

O experimento foi conduzido no Laboratório de Genética de Leguminosas Forrageiras da Universidade Federal Rural de Pernambuco, para cuja execução foram utilizadas sementes de 14 acessos (amostras populacionais) de Stylosanthes scabra, de três regiões ecogeográficas do Estado de Pernambuco: Mata, Agreste e Sertão, pertencentes ao Banco de Germoplasma de Leguminosas Forrageiras da UFRPE. As sementes passaram por uma análise de pureza e estavam depositadas há três meses 
em câmara a $14^{\circ} \mathrm{C}$. A Tabela 1 mostra dados geoclimáticos dos municípios onde foram coletadas as amostras populacionais. $\mathrm{O}$ delineamento experimental foi inteiramente casualizado, em arranjo fatorial de 14 x 2, representando populações e tratamentos, escarificado e não escarificado, com quatro repetições de 50 sementes.

Tabela 1. Dados geoclimáticos dos locais de coleta de amostras das populações estudadas

\begin{tabular}{lccc}
\hline Populações & Altitude $(\mathrm{m})$ & $\begin{array}{c}\text { Temp. Média } \\
\text { Anual }\left({ }^{\circ} \mathrm{C}\right)\end{array}$ & $\begin{array}{c}\text { Prec. Média } \\
\text { Anual }(\mathrm{mm})\end{array}$ \\
\hline Recife & 15 & 24,0 & 1651,3 \\
Itamaracá & 25 & 25,6 & 236,3 \\
Paulista & 50 & 24,5 & 1651,3 \\
Gaibu & 3 & 25,3 & 2213,9 \\
Angelim & 620 & 24,0 & 640,1 \\
Tacaimbó & 530 & 26,0 & 661,2 \\
Sanharó & 620 & 22,4 & 708,5 \\
Garanhuns & 820 & 20,7 & 782,4 \\
São Caetano & 540 & 22,7 & 478,8 \\
Serra Talhada & 450 & 24,5 & 693,9 \\
Triunfo & 900 & 22,0 & 1227,6 \\
Ibimirim I & 520 & 24,5 & 453,5 \\
Ibimirim II & 600 & 24,5 & 453,5 \\
S. Cruz da B. Verde & 800 & 22,5 & $1227,6 *$ \\
\hline
\end{tabular}

Fontes: Instituto Nacional de Meteorologia (INEMET) 1997

Empresa Pernambucana de Pesquisa Agropecuária (IPA) 1997

* Pluviosidade da estação mais próxima (Triunfo)

As sementes foram submetidas ao ácido sulfúrico concentrado 97\%, por $8 \mathrm{~min}$ (Barros, 1978) e, posteriormente, lavadas em água corrente e passadas rapidamente por uma

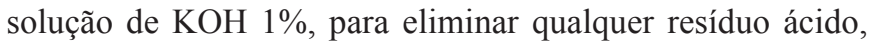
deixando-se secar por algumas horas à sombra, em temperatura ambiente; a seguir, foram submetidas ao teste de germinação. As sementes não escarificadas foram submetidas a um tratamento fitossanitário com uma solução de hipoclorito de sódio na proporção de $3: 1$, por cinco minutos, depois lavadas em água corrente, secadas à sombra, e postas para germinar em caixas de plástico tipo Ger-box em temperatura ambiente. $\mathrm{O}$ substrato utilizado foi o papel de filtro (SP) umedecido com água destilada.

A contagem e a remoção das sementes germinadas foram feitas diariamente durante 15 dias, obtendo-se a percentagem total de germinação no final do teste; considerou-se germinada a semente que desenvolveu uma radícula de $5 \mathrm{~mm}$ de comprimento.

Realizou-se a análise de variância segundo o esquema fatorial $14 \times 2$. Utilizou-se o teste de Tukey a $5 \%$ de probabilidade, quando $\mathrm{F}$ foi significativo, enquanto os dados de percentagem de germinação foram transformados em $\operatorname{arcsen} \sqrt{\%}$, segundo Steel \& Torrie (1960).

\section{RESULTADOS E DISCUSSÃO}

A análise de variância dos dados demonstrou haver diferenças altamente significativas entre e dentro das populações, nos dois tratamentos: sementes escarificadas e não-escarificadas (Tabela 2); constatou-se que apenas para a população Gaibu não houve significância entre os dois tratamentos, tendo-se verificado que, enquanto nas sementes não escarificadas Gaibu apresentou o maior percentual de germinação, nas sementes escarificadas teve o menor. Provavelmente, não houve resposta da população Gaibu à escarificação, por ser a cutícula fator secundário de dormência nesta população. A significância de interação mostra que as populações têm comportamento diferencial em função do ambiente específico, isto é, cada população se comporta de acordo com a sazonalidade ambiental. Obteve-se um percentual de germinação das sementes nãoescarificadas variando de 7,60 (Ibimirim II) a 38,88\% (Gaibu); já na germinação de sementes escarificadas, a variação percentual foi de 41,48 a 69,51\%, para Gaibu e Serra Talhada, respectivamente (Tabela 2).

Tabela 2. Percentual médio de germinação para avaliação do grau de dormência de sementes não escarificadas e escarificadas de populações de Stylosanthes scabra das três Regiões: Mata, Agreste e Sertão do Estado de Pernambuco

\begin{tabular}{lrlrl}
\hline \multirow{2}{*}{ Populações } & \multicolumn{4}{c}{ Média $^{*}$} \\
\cline { 2 - 5 } & \multicolumn{2}{c}{ Sementes Não } & $\begin{array}{c}\text { Sementes } \\
\text { Escarificadas }\end{array}$ \\
\hline Recife & 12,86 & BEF & 47,05 & ADE \\
Itamaracá & 14,86 & BDEF & 67,06 & AAB \\
Paulista & 26,52 & BABCD & 57,19 & AABCD \\
Gaibu & 38,89 & AA & 41,48 & AE \\
Angelim & 22,52 & BBCDE & 66,46 & AAB \\
Tacaimbó & 17,50 & BCDEF & 66,46 & AAB \\
Sanharó & 31,22 & BAB & 67,77 & AAB \\
Garanhuns & 20,00 & BBCDE & 55,76 & ABCD \\
São Caetano & 27,61 & BABCD & 60,99 & AABC \\
Serra Talhada & 26,11 & BBCD & 69,51 & AA \\
Triunfo & 14,64 & BDEF & 67,80 & AAB \\
Ibimirim I & 12,68 & BEF & 48,75 & ACDE \\
Ibimirim II & 7,61 & BF & 57,18 & AABCD \\
Santa Cruz da & 29,42 & BABC & 60,22 & AABC \\
\multicolumn{1}{c}{ Baixa Verde } & & & & \\
\hline Média & 21,60 & & 59,55 & \\
\hline Média Geral = $=40,55$ & & & & \\
C.V.\% $=12,70$ & & & & \\
\hline
\end{tabular}

* Dados transformados em arcsen $\sqrt{\%}$ média de quatro repetições

Na linha, os valores seguidos de pelo menos uma mesma letra minúscula e, nas colunas, os valores seguidos de pelo menos uma letra maiúscula, não diferem estatisticamente pelo teste de Tukey, a $5 \%$ de probabilidade

De acordo com os resultados apresentados na Tabela 2, existe um percentual médio para germinação de sementes não-escarificadas, de $21,60 \%$, enquanto para sementes escarificadas quimicamente tem-se um percentual de germinação de $59,55 \%$. O percentual de germinação de sementes não escarificadas representa $36,28 \%$ do percentual de sementes escarificadas. Barriga (1979) trabalhando com oito populações de $S$. humilis, encontrou valores divergentes dos obtidos neste trabalho: índices médios próximos de $100 \%$ de germinação para sementes escarificadas com lixa, enquanto a média obtida entre as populações para as sementes não-escarificadas aproximou-se de 5\%; a escarificação química não teve a mesma eficácia da escarificação mecânica, porém vale salientar que, no tratamento de sementes escarificadas, todas as médias de germinação foram superiores à média geral. A população Serra Talhada, com o maior percentual de germinação (superior à média geral em 71,33\%), bem como as populações Triunfo, Sanharó, Itamaracá, Angelim e Tacaimbó, com média de germinação mais de $60 \%$ 
acima da média geral, indicam uma adaptabilidade média a todos os ambientes (pois foram superiores à media geral em mais de $50 \%$ ) o que leva à possibilidade de selecioná-las tomando-se como referência a média geral das populações, com percentual acima dela.

Aos quinze dias após o início do experimento, as sementes que não germinaram apresentavam-se duras, não intumescidas, chegando-se a conclusão de que, neste comportamento, atua fortemente o componente genético. Donnely et al. (1972) trabalhando com o gênero Vicia; Forbes \& Wells (1968) e Gladstone (1970) trabalhando com Loupinus, comentam que a característica de impermeabilidade à água apresentada pelo tegumento da semente possui controle genético qualitativo.

A variação observada no percentual de germinação entre as populações indica, provavelmente, diferentes estratégias de adaptação a diversos habitats (Tabela 2). Paterniani \& Martins (1979) trabalhando com Stylosanthes guianensis, evidenciaram a existência de ampla variabilidade entre as populações estudadas no que se refere ao grau de dormência das sementes, variabilidade que se deve relacionar ao componente genético, pois as populações eram de várias localidades e foram submetidas a condições ambientais uniformes e controladas, condições estas semelhantes às desta pesquisa.

Argel \& Humphreys (1981) observaram que a impermeabilidade do tegumento da semente de Stylosanthes hamata cv. Verano estava associada à temperatura que prevalecia durante a formação das sementes. Em testes de germinação realizados por ocasião da colheita, foram observadas elevadas percentagens de sementes duras quando a temperatura do ar durante o período de formação da semente era mais alta, ocorrendo redução gradativa desse percentual à medida que a temperatura na referida fase se tornava mais baixa. Este trabalho demonstra a influência de um componente ambiental sobre a variação do grau de dormência das sementes de S. hamata cv. Verano.

Embora se tendo observado (Tabela 1), que a temperatura anual de Gaibu apresentou pouca diferença da de Ibimirim, na precipitação média anual existe grande diferença de valores, interferindo na umidade relativa, sendo maior em Gaibu, fator este que, associado a outros, deve ter influenciado na germinação das sementes. Estudos têm demonstrado que a variação do micro habitat dentro e entre a população pode influenciar nos caracteres de plântulas, no crescimento e na reprodução (Kadmon e Shmida, 1990; Schwaegerle \& Levin, 1990; Kelly, 1992).

Identificando-se essas populações através das regiões procedentes e se determinando a média de germinação para as populações de cada região, verificou-se que a menor média de germinação foi para as populações do Sertão; assim, confirmase a hipótese de que a dormência deve ser uma estratégia adaptativa que confere, às populações, maior adaptação ao habitat onde se encontram. Num ambiente instável, as condições não devem ser suficientemente seguras para o pronto estabelecimento e desenvolvimento da plântula, logo após a sua germinação, caso em que a dormência de sementes pode constituir-se numa eficiente estratégia de sobrevivência e perpetuação da espécie, fenômeno que possibilita a formação de um banco de sementes no solo, uma reserva que permanece no solo e só germina quando as condições são favoráveis, não só para a germinação mas, principalmente, para o completo estabelecimento e desenvolvimento nas plântulas (Martins \& Jain, 1979).

A impermeabilidade do tegumento é um mecanismo de alto valor adaptativo, característica comum a muitas espécies de leguminosas forrageiras, entre elas as do gênero Stylosanthes (Rolston, 1978).

De acordo com Mayer \& Poljakoff-Mayber (1975), Popinigis (1977) e Humphreys (1981) a origem ou causa da dormência de sementes pode estar relacionada ao tegumento ou a estruturas associadas que impeçam a entrada de água, afetem as trocas gasosas, contenham substâncias inibidoras da germinação etc; por outro lado, pode também estar associada ao embrião, que pode ser imaturo ou rudimentar, fisiologicamente inativo ou, ainda, sofrer de dormência secundária induzida por mudança ambiental posterior à maturação da semente.

Vale salientar que, neste trabalho, todas as sementes não germinadas foram consideradas dormentes, visto que, após os 15 dias de observação, encontravam-se duras, não intumescidas; no entanto, não se pode afirmar a que causa, dessas supracitadas, a referida dormência está relacionada.

Diante de tantas possibilidades, é importante lembrar que a dormência das sementes é um dos mais importantes fenômenos ocorridos na evolução das espécies para superar as condições ambientais adversas e, também, para colonizar novos habitats não apropriados ao crescimento durante $o$ ano.

\section{CONCLUSÕES}

1. A menor média de germinação sem estímulo das sementes de S. scabra do Sertão, região instável, ratifica a hipótese de que a dormência deve ser uma estratégia adaptativa que confere às populações maior adaptação ao habitat natural onde se encontram.

2. A percentagem de germinação das sementes nãoescarificadas variou de 7,61\% (Ibimirim II) a 38,89\% (Gaibu). Já na germinação de sementes escarificadas, a variação percentual foi de 41,48 a $69,51 \%$, para Gaibu e Serra Talhada, respectivamente.

\section{REFERÊNCIAS BIBLIOGRÁFICAS}

ARGEL, P.I.; HUMPHREYS, L.R. Climatic influences during flowering on seed dormancy and seed formation of Stylosanthes hamata cv. Verano. In: International Grassland Congress, 14., Lexington. Proceedings.... Boulder: Westview Press, 1981, p.384-386.

BARRIGA, J.P. Autoecologia de Stylosanthes humilis H.B.K.: Avaliação da variabilidade morfológica e estudos da biologia da semente. Piracicaba: ESALQ/USP 1979. 97p. Dissertação Mestrado

BARROS, L. de M. Avaliação da variabilidade de caracteres agronômicos em populações de Stylosanthes guianensis (Aubl.) Sw. Piracicaba: ESALQ/USP 1978. 108p. Dissertação Mestrado

BATTISTIN, A. Estudo biossistemático de diferentes taxons do gênero Stylosanthes Sw. (Leguminosae-Papilionoideae). Piracicaba: ESALQ/USP, 1981. 106p. Dissertação Mestrado 
CARVALHO, N.M.; NAKAGAVA, J. Sementes, ciência; tecnologia e produção. Jaboticabal: Funet, 2000. 588p.

DONNELLY, E.D. Persistence of hard seed in Vicia lines derived from interespecific hibrydization. Crop Science, Madison, v.10, p.661-662, 1970.

DONNELLY, E.D.; WATSON, J.E.; McGUIRE, J. A. Inheritance of hard seed in Vicia. The Journal of Heredity, Madison, v.63, p.361-365, 1972.

FORBES, F.; WELLS, H.D. Hard and soft seededness in blue lupine. Lupinus angustifolius L.: Inheritance and phenotype classification. Crop Science, Madison, v.8, p.195-196, 1968.

GLADSTONES, J.S. Lupinus as crop plants (review article). Field Crop Abstracts, Australia, v.23, p.123-148, 1970.

HUMPHREYS, L.R. Environmental adaptation of tropical pasture plants. London: Macmillan Publishers Ltda., 1981. 261p.

KADMON, R.; SHMIDA, A. Patterns and causes of spatial variation in the reproductive success of a desert annual. Oecologia, Berlin, v.83, p.139-144, 1990.

KELLY, C.A. Spatial and temporal variation in selection on correlated life-history traits and plant size in Chamaecrista fasciculata. Evolution, College Park, v.46, n.6, p.1658-1673, 1992.

MARTINS, P.S.; JAIN, S.K. Role of genetic variation in the colonizing ability of rose clover (Trifolium hirtum All.). American Naturalist, California. v.114, p.591-595, 1979.

MAYER, A. M.; POLJAKOFF-MAYBER, A. The germination of seeds. 2. ed. Oxford: Pergamon Press Ltda., 1975. 192p.
PATERNIANI, M.L.S.; MARTINS, P.S. Variabilidade genética da dormência de sementes em populações de Stylosanthes guianensis (Aubl.) Sw. (leguminosae- Papilionoideae). Piracicaba: Instituto de Genética/ESALQ, 1979. Relatório Científico

POPINIGIS, F. Fisiologia da semente. Brasília: Ministério da Agricultura/AGIPLAN, 1977. 289p.

REIS, M.S. Autoecologia de diferentes espécies de Stylosanthes Sw.: Análise da alocação de energia e estudos da biologia da semente. Piracicaba: ESALQ/USP, 1984. 170p. Tese Doutorado

ROBERTS, E.H. Dormancy: A factor affecting seed survival in the soil. In: ROBERTS, E. H. Viabilitly of Seeds. New York: Syracuse University, 1972. p.321-359.

ROLSTON, M.P. Water impermeable seed dormancy. The Botanical Review, Lancaster, v.44, n.3, p.365-396, 1978.

SCHWAEGERLE, K.E.; LEVIN, D.A. Environmental effects on growth and fruit production in Phlox drummondii. Journal Ecology, Oxford, v.78, p.15-26, 1990.

SILVA, L.M.M.; MATOS, V.P. Estudo sobre dormência de sementes de mulungu (Erythrina velutina Wild .); viabilidade e presença de inibidores. Ciência Agrícola, Maceió, v.2. n.6, p.29-39, 1993/94.

STEEL, R.G.D.; TORRIE, J.H. Principles and procedures of statistics. New York: McGraw-Hill, 1960. 481p.

VIEIRA, I.C.G. Distribuição fracionária de energia e biologia da semente de Stylosanthes Angustifolia Vog. (Leguminosae Papilonoideae). Piracicaba: ESALQ/USP, 1987. 128p. Dissertação Mestrado 